\title{
Healthy Management of Menopause: Exploring Issues and User Requirements for Mobile Intervention
}

\author{
Aznoora Osman ${ }^{1 *}$, Nur Emieliana Izzatie Ahmad Noraimi ${ }^{2}$, Nadia Abdul Wahab ${ }^{3}$ \\ ${ }^{1,2,3}$ Faculty of Computer and Mathematical Sciences, \\ Universiti Teknologi MARA Perlis Branch, Arau Campus, 02600 Arau, Perlis, Malaysia \\ Corresponding author: *aznoora@uitm.edu.my \\ Received Date: 18 August 2021 \\ Accepted Date: 4 September 2021 \\ Published Date: 20 September 2021
}

\section{HIGHLIGHTS}

- This study investigates the current issues surrounding women when going through the menopause phase

- It also examines the importance and advantages of mHealth application for women.

- It reveals the most important functional requirements of a mobile app to manage menopause symptoms and to provide emotional support

- It highlights those women should be given support and opportunity to educate themselves with necessary knowledge to embrace the menopause stage.

\begin{abstract}
Designing and developing a mobile health intervention that focuses on menopausal symptom management and emotional support for women should be grounded by some knowledge about their problems and needs. Therefore, to gather information about the issues surrounding women in their menopausal phase, review of literatures pertaining to the topic was conducted, followed by a brief preliminary investigation (PI) using online survey method which was administered to Malaysian women for two weeks. The purpose of PI was to examine their awareness about menopause, namely its phases and symptoms management, as well as methods of information searching on menopause. Respondents were also inquired about their requirements from mobile app to support management of menopause. A total of 30 respondents answered the survey, with majority of them were between the ages of 40 and 59 years old. It was discovered that menopausal women had experienced variety of symptoms, some could be intense more often than the others, and they use diary or book to record these symptoms, which is deemed ineffective. It is imperative to help Malaysian women to manage this unavoidable phase of their lives in a more convenient approach. Therefore, a mobile app that supports symptoms management, and provides educational and motivational tips in Malay language is proposed.
\end{abstract}

Keywords: menopause, symptoms management, mobile health intervention, multimedia learning

\section{INTRODUCTION}

Menopause is a natural part of ageing that is unavoidable in women's lives especially when reaching the ages of late 40s and early 50s. Menopause is a natural phenomenon in a woman's life. Every woman will experience a phase of menopause where it marks the cessation of menstruation or the last menstruation in 
a woman's life. It is a condition that every woman faces in later life and can have many associated effects, which might disrupt the quality of life. Women have to brave through this biological phase because it involves physical and hormonal changes that cause them to feel pain and discomfort, thus trigger states of emotional roller-coaster. The symptoms of menopause for every woman are different. Although women experience such symptoms, they are not adequately examined because they lack the knowledge on the concept and management of menopause. Fortunately, technology such as mobile application can be employed to help menopausal management effectively. The following section will discuss some literatures pertaining to menopause and its management, as well as about mobile app that are available to support women in their menopause journey.

\section{LITERATURE REVIEW}

\section{Menopause}

According to Ilankoon, Samarasinghe \& Elgan (2021), menopause can be defined as the end of menstruation due to the loss of ovarian follicular activity. It is a natural stage or a normal physiological change in the ageing process that marks the end of menstruation following the last menstrual period in the previous 12 months (Dutta, Dcruze, Anuradha, Rao \& Rashmi, 2012) and occur in women life after the age of 45 years and above (Saljoughian, 2018). Menopause can be categorized into three stages which is perimenopause, menopause and postmenopause. Women spend one-third of their life in menopause phase, where beginning from menopausal transition period, women will face various type of menopause symptoms during perimenopause (Lee, Bon-Chang, Hee-Seok, Park, Cho \& Jun-Dong, 2015). There are several symptoms that might arise, and they generally differ amongst women. Some women experience one or two, which may be mild, while others have more severe and distressing symptoms. However, many women are unaware that some of their symptoms are connected to perimenopause and menopause. According to Du, $\mathrm{Xu}$, Huang, Zhu and He (2020) during the menopause phase, the termination of ovarian hormonal action, particularly the low level of estrogens, can cause vasomotor. Vasomotor symptoms refer to hot flashes and sweating, heart discomfort, sleeping problems, depressive mood, impaired memory, vaginal dryness, sexual problems, and joint or muscular complaints (Ryu, Park, Kim, Yi, Shin, Hur \& Kim, 2020), which occurs due to the constriction or dilation of blood vessels (Wilson, 2020). Most women experience more than one of the aforementioned symptoms during their perimenopausal and postmenopausal periods. In reality, many women are affected by menopausal symptoms, which may have a negative impact on their family, career, and life (Newson \& Panay, 2018).

\section{Women's Experience with Menopause}

It was discovered that $59 \%$ of women working as teachers had poor knowledge regarding menopause and only $41 \%$ had moderate to excellent knowledge of menopause (Alotaibi, Yakout \& Moawad, 2019). Previously, Harun, Kamaruddin, Alias and Haron (2015) found that women still lack knowledge about menopause transition and psychological change during menopause stage. Additionally, Harun et al. (2015) also revealed that most women normally seek information from lay sources like newspaper, magazines and other women. This is unfortunate because it seems that women in Malaysia were still clueless about menopause. Adding to the agony, while dealing with pain and discomfort, women in Malaysia receive lack of support from family and friends. Many menopausal women consider the supports they received are negative rather than positive ones that they hope to get from loved ones (Hassan, Nik Hussain, Sulaiman, Abdul Kadir, \& Mat Nor, 2020). Not only that, some women also have problems with depression and anxiety caused by hormonal changes causing them to perceive menopause as a lonely journey, hence support from close friends and loved ones is ultimately desired by women in menopausal phases.

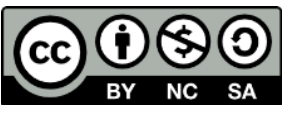


In light of this, women should be given support and opportunity to educate themselves with necessary knowledge to embrace the menopause stage because by being more knowledgeable, it could empower women to cope better with the symptoms, pains, discomforts and bodily changes. The Sustainable Development Goal (SDG) 3 has the aim to ensure healthy lives and promote well-being for all at all ages, thus upgrading support for women's health are paramount. Therefore, to address SDG 3, this study was embarked to design and develop a mobile health intervention for menopause symptoms management and emotional support. If women can grasp a better understanding about menopause along with the symptoms tracking using mobile application, women could have a happier and healthier menopausal experience.

\section{Mobile Health Management}

Mobile application is seen as a promising technology to support management of health and wellness. Over the past years, the idea of collecting personal health information through mobile health apps has become increasingly popular. Gkrozou, Tsonis, Godden, Siafaka \& Paschopoulos (2019) claimed that development of mHealth app has the potential to turn smartphones into handy medical devices, which will surely lead to better healthcare systems around the worldwide. This is apparently true because according to Bol, Helberger $\&$

Weert (2018), the are 3,195,204 active mobile apps available in the iTunes app store and 3,612,250 active apps in the Google Play store, with 95,851 and 105,912 apps were categorized as Health and Fitness respectively.

The development of mHealth platform to support women going through the menopause is increasing around the world. Using mobile technologies can help women in menopausal phase because nowadays mobile application is an easy and faster technologies that people use. In addition, using application is a trend for manage daily routine since user can use it anywhere and anytime. Currently, there are many applications for menopause management, that help women in recording the menstrual dates and record the symptoms of menopause and provide information about user's current health status (Lee, Bon-Chang, Hee-Seok, Cho \& Jun-Dong, 2015).

Recent development of technologies in mobile health (mHealth) has shown more attention are given to menopausal women, for instance Gkrozou et al. (2019) revealed that 91\% menopause apps were intended for public use and provided specialized information serving as a medical tool and data recording system. Additionally, the research found that $9 \%$ females tend to use mHealth application compare to men with only $4 \%$. This is a sign that mHealth application for menopausal tends to grow and can help women in the management of menopause.

Nevertheless, mHealth apps that educate women to manage the menopausal stage along with symptoms tracking and emotional support are scarce. Furthermore, many of the existing applications use English language, which could be barrier for those who have poor grasp and fluency, and for Malaysia, since our mothertounge is Malay language, having mobile apps using our national language would be preferrable to attract users to use for menopausal tracker and support.

\section{Symptoms Management with Tracker}

There are so many symptoms that women can associate with the menopause that it is sometimes hard to keep track. Menopause symptom tracker is a tool that can be used by women to keep track the menopause symptoms. Jacobs (2021) argued that technology has now advanced to the point where it helps women in tracking menstrual cycles and fertility with the push of a button in application and eventually can know 
when to expect menstruation and ovulation. This same technology benefits women when they go through the menopausal transition. Menopause symptoms tracker tool is important in diagnosing the menopause in women lives. Other than that, menopause symptoms tracker can be applied as a self-tracking technology where women can monitor the menopause symptoms and record it by themselves using technology like mobile application. Menopause tracking application is a very common mobile application that can be used to track the symptoms of menopause. In Google Play Store, there are a lot of menopause-related applications available to provide various kinds of functionalities to the user.

Homewood (2019) claimed that self-tracking technology has been used to give a solution for menopause transaction and this technology is applied with a set of end goal to mitigate poor metabolic and cardiovascular health that accompanies menopause, where users are coached towards good health through symptom monitoring and personalized goal setting based on self-reported data.

\section{PRELIMINARY INVESTIGATION}

After performing literature reviews about menopause issues and potential of mobile health intervention, there is a need to gather some insights into the reality of menopause issues among Malaysian women, especially their fundamental knowledge about this phase, their information seeking methods and problems they face with regards to symptoms tracking and emotional support. Furthermore, their actual requirements for a mobile app to support effective management of menopause must be investigated. Therefore, a preliminary investigation (PI) was conducted using online survey method. A Google form containing the survey was shared via Whatsapp for two weeks in the month of April 2021. It was clearly stated in the introdutory section of the survey that only Malaysian women from the ages of 18 to 60 years old could participate and that their participation was voluntary. A total of 30 respondents answered the survey.

\section{FINDINGS AND DISCUSSIONS}

This section discusses findings from the PI. Demographic information of respondents is presented first, followed by their information seeking methods, symptoms that they experience and its management, while their basic knowledge about the total number of phases in menopause is presented at the end.

\section{Demographic Information}

Table 1 summarises the demographic information of respondents. Almost all respondents were married, while majority of them were between the ages of 40 and 59 years old. Almost half of them had higher degree qualifications (Master or PhD), and quarter of them had either SPM or STPM and its equivalents respectively. For occupation status, half of the respondents were working in semi-professional jobs, while almost half were professionals. Less than $10 \%$ were self-employed.

Table 1: Demographic Information of Respondents

\begin{tabular}{|c|c|}
\hline Criteria & Percentage \\
\hline Marital status & $\begin{array}{ll}\text { - } & \text { Married }(93.3 \%) \\
\text { - } & \text { Single }(6.7 \%)\end{array}$ \\
\hline Age & $\begin{array}{ll}\text { - } & 50-59(46.7 \%) \\
\text { - } & 40-49(40 \%)\end{array}$ \\
\hline
\end{tabular}

Copyright@ 2021 UiTM Press. This is an open access article under the CC BY-NC-SA (https://creativecommons.org/licenses/by-nc-sa/4.0//) 


\begin{tabular}{|l|ll|}
\hline & $\bullet$ & $30-39(6.7 \%)$ \\
\hline Education level & $\bullet$ & Master, PhD (43.3\%) \\
& $\bullet$ & STPM, Diploma, Matriculation (26.7\%) \\
& $\bullet$ & SPM $(26.7 \%)$ \\
& $\bullet$ & First degree (3.3\%) \\
\hline Occupation status & $\bullet$ & Professional (43.3\%) \\
& $\bullet$ & Semi-professional (50\%) \\
& $\bullet$ & Self-employed (6.7\%) \\
\hline
\end{tabular}

\section{Information Seeking Methods}

For information seeking methods, respondents had to answer five related questions, namely (1) whether they have asked medical/health expert about menopause, (2) how they search for information, (3) difficulty of obtaining relevant information, and (4) sufficiency of information gained. Table 2 describes these questions along with corresponding percentage. It was alarming, yet not surprising that most respondents have never asked about menopause to medical experts. This was because, when searching for information, they have the options of browsing the Internet, or read from printed sources like books/magazines, and lastly ask peers or family members. This is evident in the third question, where they could tick more than one answer. It was discovered that $86.7 \%$ relied heavily on Internet search, followed by books/magazines (43.3\%), while friends and family were the go-to persons to ask about menopause (40\%). More than half admitted that they have experienced difficulty in searching for information, and perhaps because of that, in question 4 almost all of them (96.7\%) answered the information they gained were insufficient.

Table 2: Question Pertaining to Information Seeking Methods

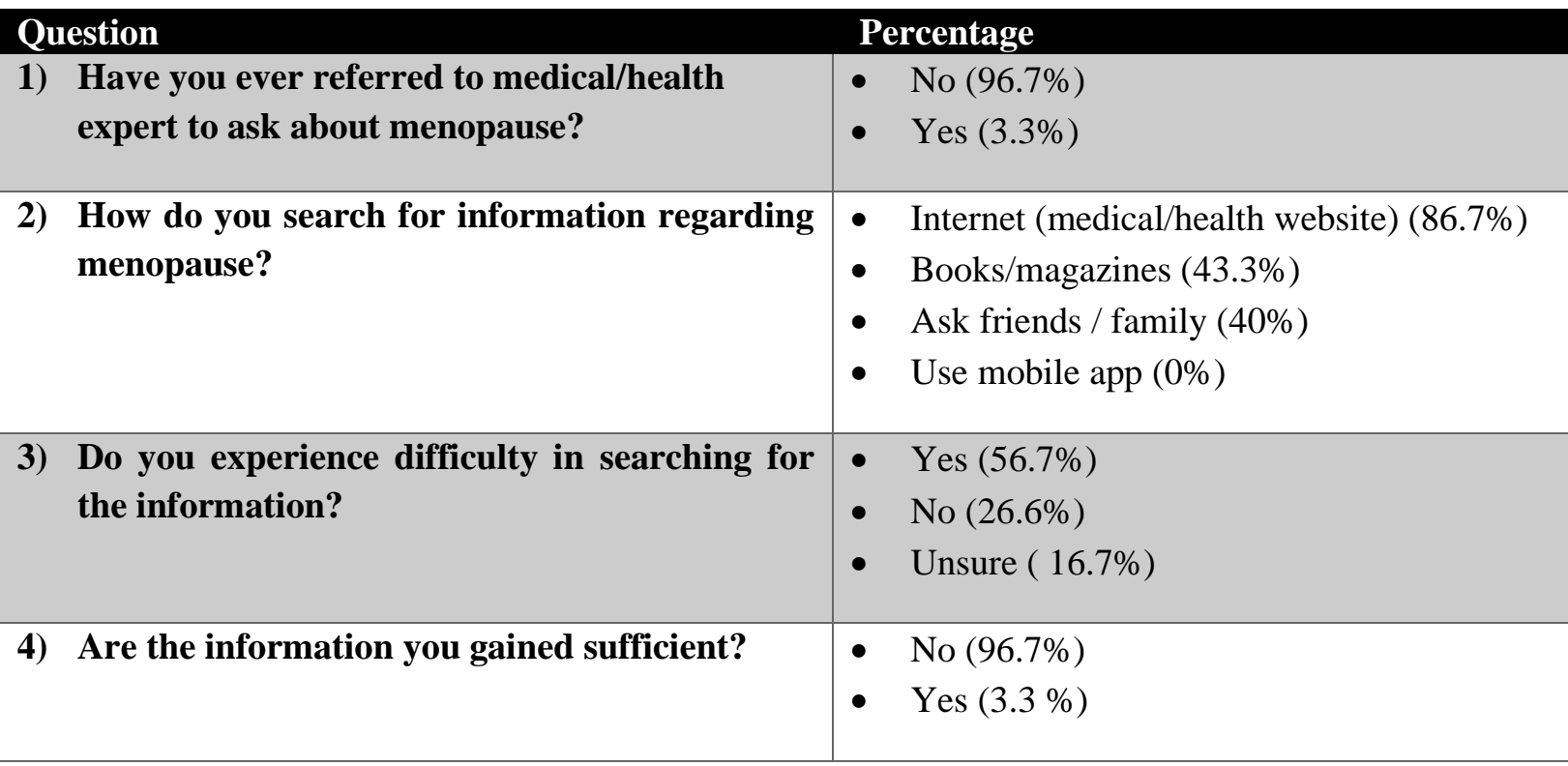




\section{Menopause Symptoms and Management}

For women who have started menopause phases, they were required to answer two questions pertaining to the symptoms that they usually experience, and how they keep record about it. Those who have not yet reached the menopause phase could choose an option "Not related to me". It was revealed that women would experience certain symptoms more often, where between $40 \%$ and $50 \%$ of them chose hot flushes as the major symptoms, followed by night sweats, difficulty to fall asleep, difficulty to focus, feeling of anxiety, and vaginal dryness. Other than that, $20 \%$ of these women also had problems with weight gain and headache. Additionally, only one experienced heart palpitations and another one respondent had painful tingling sensations in the feet. As we can see, the symptoms are aplenty, and would be more intense for some women than the others.

Symptoms management is a vital process that must not be overlooked, but instead must be carefully tracked to help women to take precautions and necessary actions in reducing or even eliminating pains and discomfort. For another question about symptoms tracking, it was discovered that menopausal women tend to use diary, books, notepad and sticky notes to record the symptoms. This is not efficient and effective because notes could be misplaced or damaged, and women need to carefully view each sheet to identify the frequency of symptoms. Consequently, women cannot keep track of the menopause symptoms properly and it might affect their ability to manage menopause effectively.

\section{Basic Knowledge About Phases in Menopause}

There was only one question in this dimension, where respondents were asked about total number of phases in menopause. It was very surprising because $76.7 \%$ did not know the correct answer which is three phases. With all the Internet searching, and reading from printed materials like books and magazines, clearly respondents could not obtain relevant information in a more structured manner, thus indicating the need to educate them via a more engaging medium, for example mobile app.

\section{The Needs for Emotional Support}

In this dimension, women were asked if they needed emotional support, motivation and positive quotes while going through the menopause phases. $46.7 \%$ (who were women in menopausal phases) answered Yes, while only $13.3 \%$ answered Maybe they need it. Another $33.3 \%$ were women who had not experience menopause, therefore they chose the option "Not-related to me". Women were asked whether they receive any emotional support, and sadly $33.3 \%$ answered they did not receive it. Another $26.7 \%$ did however receive support from husbands and other menopausal women. Menopause is an important phase in women's lives but very often receive little to no attention, probably due to our own culture that perceives it as a sensitive or taboo issue.

\section{The Needs for Mobile App as Symptoms Management Tool}

In the last question, respondents were inquired whether they would want to use a mobile app in Malay language that serves as symptoms management tool and emotional support system. All 30 of them answered Yes, so this could be a sign that women, regardless of their age, were interested to use mobile app to help them in managing menopause effectively.

\section{Reflections from the Findings of Literature Review and PI}

By conducting review of literature pertaining to menopause and mHealth application, and through the findings of PI, there is a need to support Malaysian women to manage menopause phase effectively, 
concerning to its symptoms management and emotional support. Since mobile applications for menopause provide many advantages for women, this study will enter its second phase which is to design and develop mobile app called "MenoSmile" that can assist women to cope with the journey. It was revealed that four main functional requirements must be fulfilled which are (1) Use Malay language, (2) Allow to record and track menopausal symptoms using symptoms tracker, (3) Provide emotional support through recommendation and tips to reduce symptoms, and (4) Provide access to easily comprehensible information about menopause. Mobile health design principle (Lienhard and Legner, 2017) and multimedia learning principles (Mayer, 2014) will be used as main guides in designing the mobile app's user interface and contents presentation. Mobile health design principle (Lienhard and Legner, 2017) was selected because it guides developers to build a reliable Mhealth app, for instance its first design principle recommended that the app should consist of four functional components that guide a patient: instruction, setup, clinical measurement, and analysis and feedback, while also making sure that it is built using robust medical knowledge base. Mayer's Principle of Multimedia Learning is based on empirical evidence how human mind works, that is we process information using eyes (visual) and ears (audio). By adapting to its recommended learning principles, it will help in developing an effective learning resource for menopausal women. Figure 1 depicts the research model for MenoSmile mobile app.

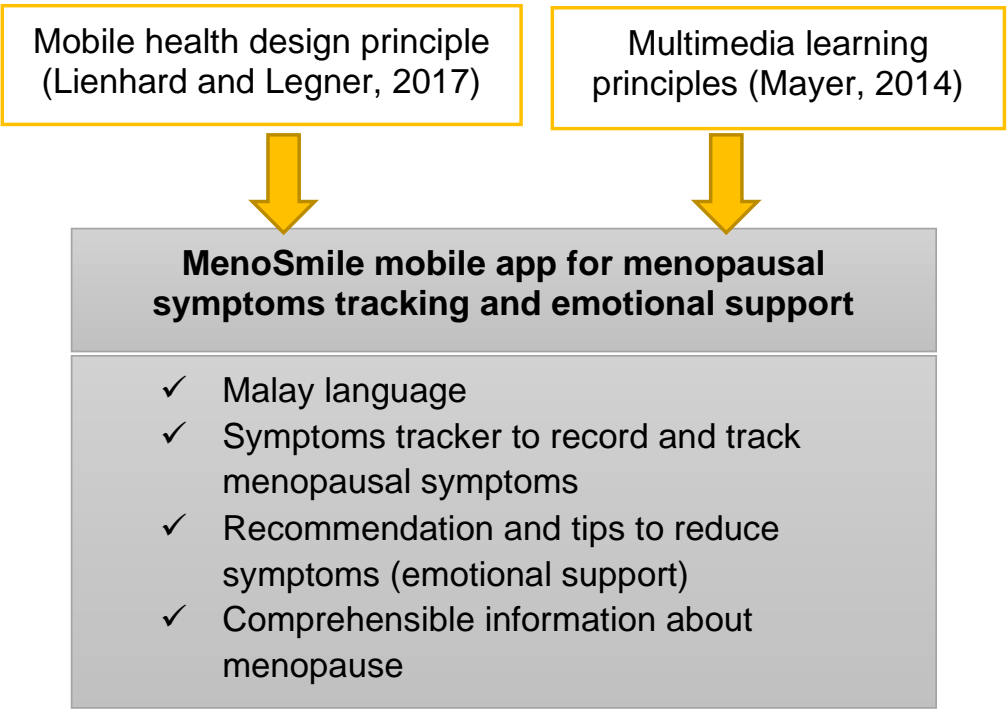

Figure 1: Research Model for MenoSmile Mobile App

\section{CONCLUSION AND RECOMMENDATIONS}

The PI was briefly administered and its findings were based on a small number of respondents. Although it does not represent the whole population's experience about menopause, nevertheless, it was able to reveal some issues surrounding women especially in ensuring proper management of symptoms and sufficient emotional support, as well as requirements from a mobile app that could be developed for them. This research is important to be carried out because it will assist Malaysian women in managing their menopausal stage healthily and effectively. By using the mobile app, it is envisioned that women could enhance their understanding about menopause, and consequently motivate them to embrace this phase in their lives that is naturally unavoidable.

\section{ACKNOWLEDGMENTS}

We would like to thank all respondents of the preliminary investigation for their willingness to participate in the study. 


\section{REFERENCES}

Alotaibi, S., Yakout, S. M. H., \& Moawad, S. M. (2019). Knowledge And Health Promoting Lifestyle Behaviors About Menopause Among Perimenopausal Female Teachers. Journal of Nursing Education and Practice, 9(6), 113. https://doi.org/10.5430/jnep.v9n6p113.

Bol, N., Helberger, N., \& Weert, J. C. M. (2018). Differences In Mobile Health App Use: A Source of New Digital Inequalities? Information Society, 34(3), 183-193. https://doi.org/10.1080/01972243.2018.1438550.

Du, L., Xu, B., Huang, C., Zhu, L., \& He, N. (2020). Menopausal symptoms and perimenopausal healthcare-seeking behavior in women aged 40-60 years: A community-based cross-sectional survey in Shanghai, China. International Journal of Environmental Research and Public Health, 17(8). https://doi.org/10.3390/ijerph17082640.

Dutta R, Dcruze L, Anuradha R, Rao S, \& Rashmi MR. (2012). A Population Based Study on the Menopausal Symptoms in a Rural Area of Tamil Nadu, India. Journal of Clinical and Diagnostic Research, 6(4), 597-601.

Gkrozou, F., Tsonis, O., Godden, M., Siafaka, V., \& Paschopoulos, M. (2019). Mobile Health (mHealth) apps focused on menopause: Are they any good? Post Reproductive Health, 25(4), 191-198. https://doi.org/10.1177/2053369119878978.

Harun. H., Kamaruddin. A., Alias. N., Haron. H @ N., (2015). Prevalence and management of menopausal symptoms in malaysian women during peri and post menopause. In: Asean Forum on ICT for Sustainable Rural Development and Knowledge Cross-Fertilization, 25-27 May, 2015, Kuala Lumpur, Malaysia.

Hassan, I. I., Nik Hussain, N. H., Sulaiman, Z., Abdul Kadir, A., \& Mat Nor, M. Z. (2020). Menopausal women's experiences of husband's support: A negative view. Enfermeria Clinica, 30, 190-193. https://doi.org/10.1016/j.enfcli.2019.07.075.

Homewood, S. (2019). Inaction as a design decision: Reflections on not designing self-tracking tools for menopause. In Conference on Human Factors in Computing Systems - Proceedings. Association for Computing Machinery. https://doi.org/10.1145/3290607.3310430.

Ilankoon, I. M. P. S., Samarasinghe, K., \& Elgán, C. (2021). Menopause is a natural stage of aging: a qualitative study. BMC Women's Health, 21(1). https://doi.org/10.1186/s12905-020-01164-6.

Jacobs, D. (2021, June 7). 5 Reasons to Track Menopause Symptoms. MenoLabs. Retrieved June 02, 2021, from https://menolabs.com/blogs/menolife/5-reasons-to-track-your-menopause-symptoms.

Lee, M., Bon-Chang, K., Hee-Seok, J., Park, J., Cho, J., \& Jun-Dong, C. (2015). Understanding women's needs in menopause for development of mhealth. In MobileHealth 2015 - Proceedings of the 2015 Workshop on Pervasive Wireless Healthcare, co-located with MobiHoc 2015 (pp. 51-56). Association for Computing Machinery, Inc. https://doi.org/10.1145/2757290.2757295.

Lienhard, K.R.; Legner, C. (2017): Principles in the Design of Mobile Medical Apps: Guidance for Those who Care, in Leimeister, J.M.; Brenner, W. (Hrsg.): Proceedings der 13. Internationalen Tagung Wirtschaftsinformatik (WI 2017), St. Gallen, S. 1066-1080. 
Mayer, R. E. (2014). The Cambridge Handbook of Multimedia Learning (2nd ed.). Cambridge University Press.

Newson, L., \& Panay, N. (2018). Managing common problems in the menopause. InnovAiT: Education and Inspiration for General Practice, 11(7), 378-386. https://doi.org/10.1177/1755738018769925.

Ryu, K. J., Park, H., Kim, Y. J., Yi, K. W., Shin, J. H., Hur, J. Y., \& Kim, T. (2020). Comparison of various menopausal symptoms and risk factor analysis in Korean women according to stage of menopause. Maturitas, 140, 41-48. https://doi.org/10.1016/j.maturitas.2020.05.023.

Saljoughian, M. PharmD, PhD Department of Pharmacy,Alta Bates Summit Medical CenterBerkeley, California. (2018, January 19). Menopause: Changes and Challenges. U.S. Pharmacist.

Wilson, D. R. (2020, April 22). What are the vasomotor symptoms of menopause?. Medical News Today. Retrieved June 02, 2021, from https://www.medicalnewstoday.com/articles/317801. 